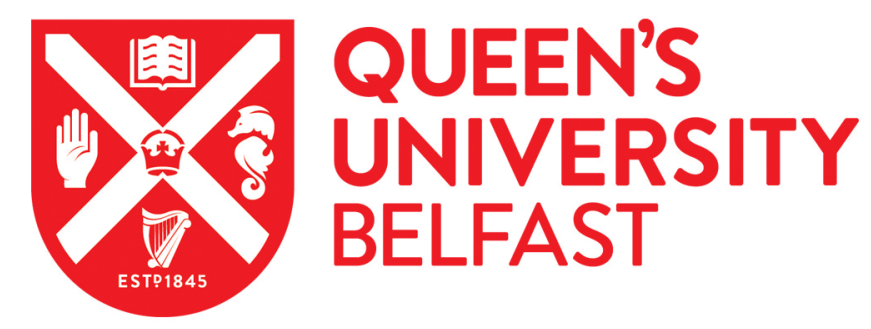

\title{
Selective High Impedance Surface Active Region Loading of Archimedean Spiral Antenna
}

Mohamad, S., Cahill, R., \& Fusco, V. (2014). Selective High Impedance Surface Active Region Loading of Archimedean Spiral Antenna. Antennas and Wireless Propagation Letters, 13, 810-813.

https://doi.org/10.1109/LAWP.2014.2314860

\section{Published in:}

Antennas and Wireless Propagation Letters

\section{Document Version:}

Peer reviewed version

Queen's University Belfast - Research Portal:

Link to publication record in Queen's University Belfast Research Portal

\section{Publisher rights}

(c) 2014 IEEE. Personal use of this material is permitted. Permission from IEEE must be obtained for all other uses, in any current or future media, including reprinting/republishing this material for advertising or promotional purposes, creating new collective works, for resale or redistribution to servers or lists, or reuse of any copyrighted component of this work in other works.

\section{General rights}

Copyright for the publications made accessible via the Queen's University Belfast Research Portal is retained by the author(s) and / or other copyright owners and it is a condition of accessing these publications that users recognise and abide by the legal requirements associated with these rights.

Take down policy

The Research Portal is Queen's institutional repository that provides access to Queen's research output. Every effort has been made to ensure that content in the Research Portal does not infringe any person's rights, or applicable UK laws. If you discover content in the Research Portal that you believe breaches copyright or violates any law, please contact openaccess@qub.ac.uk. 


\title{
Selective High Impedance Surface Active Region Loading of Archimedean Spiral Antenna
}

\author{
Sarah Mohamad, Robert Cahill, Senior Member, IEEE, and Vincent Fusco, Fellow, IEEE
}

\begin{abstract}
We show that a significant increase in the gain and front-to-back ratio is obtained when different high impedance surface (HIS) sections are placed below the active regions of an Archimedean spiral antenna. The principle of operation is demonstrated at 3,6 and $9 \mathrm{GHz}$ for an antenna design which employs a ground plane composed of two dissimilar HIS. The unit cells of the HIS are collocated and resonant at the same frequency as the $3 \mathrm{GHz}$ and $6 \mathrm{GHz}$ active regions of the wideband spiral. It is shown that the former HIS must also be designed to resonate at $9 \mathrm{GHz}$ to avoid the generation of a boresight null which occurs because the structure is physically large enough to support higher order modes. The improvement that is obtained at each of the three frequencies investigated is shown by comparing the predicted and measured radiation patterns for the free space and HIS backed antenna.
\end{abstract}

Index Terms-Spiral antennas, UWB antennas, selfcomplementary antennas, high impedance surfaces, active region.

\section{INTRODUCTION}

$\mathrm{T}$ he Archimedean spiral is a class of frequency independent circularly polarized antennas [1] which are widely used for avionics and microwave direction finding systems [2]. An in phase current relationship permits radiation from active regions where the radius of the circular bands is related to the wavelength of operation by $\lambda \approx 2 \pi \mathrm{r}$ [3]. The beam pointing direction is normal to the plane of the spiral and radiation occurs equally in the upper and lower hemispheres surrounding the antenna. For many applications it is desirable to suppress the backlobe radiation, because electromagnetic scattering from structures in close proximity to the antenna can result in pattern ripple and high crosspolarisation [4]. Moreover a significant increase in gain can potentially be obtained if a backing structure is used to transform the bidirectional pattern to a unidirectional beam. However this is not the case for the classical solution where an absorber filled cavity is placed below the antenna to reduce the backlobes [2]. For this reason low loss reflectors have recently been proposed as a means with which to simultaneously suppress backlobe radiation and increase the gain of a spiral antenna [5]. A flat

Manuscript received 30th January 2014; revised ???? 2014. Sarah Mohamad is supported by a research scholarship from the International Islamic University Malaysia.

S. Mohamad, R. Cahill and V. Fusco are with the Institute of Electronics, Communications and Information Technology, Queen's University of Belfast, Belfast, BT3 9DT, U.K. (e-mail: r.cahill@ecit.qub.ac.uk). metal plate can be used to achieve these desirable radiation characteristics at a single frequency when placed one quarter wavelength below the radiating aperture. However broadband operation is not possible using this simple arrangement because pattern distortion and impedance mismatch are often observed at higher and lower frequencies respectively. To overcome this limitation, the authors have created a more advanced ground plane design to optimize the performance of a spiral operating in discrete $1 \mathrm{GHz}$ bands between $3-10$ $\mathrm{GHz}$ [6]. The 3D structure is composed of 8 metal rings, each placed one quarter wavelength below the corresponding active region of the spiral. The purpose of this paper is to report on an alternative reflector architecture which is planar, more compact and simpler to construct than in [6]. This is obtained by replacing the metal rings with HIS segments that are designed to resonate at the same frequencies as the active regions of the wideband antenna. An additional benefit of using HIS is that the pattern can be printed on a single flat surface and placed close to the spiral arms of the antenna. This is demonstrated for a reflector structure patterned with two different $\mathrm{HIS}$ which resonate at $3 \mathrm{GHz}$ and $6 \mathrm{GHz}$. The resonant elements are miniaturized to permit selective positioning of the arrays below the active regions corresponding to these two frequencies. To simply fabrication and simultaneously minimize the cavity size, the ground plane of the HIS is separated from the spiral by a distance of $\lambda / 4$ at the highest operating frequency. Therefore the optimum electromagnetic performance is obtained at $9 \mathrm{GHz}$ without the need to pattern the surface of the HIS with array elements at this frequency. Unidirectional operation of the new arrangement is demonstrated by comparing the simulated gain, front-to-back ratio, axial ratio and the measured radiation patterns at 3,6 and $9 \mathrm{GHz}$ for the free space and HIS backed spiral antenna.

\section{Design AND Simulated Results}

A two-arm, four-turn Archimedean spiral antenna was designed to work in the $3-10 \mathrm{GHz}$ frequency range using CST MICROWAVE STUDIO software [7]. The outer and inner diameters are $60 \mathrm{~mm}$ and $4 \mathrm{~mm}$ respectively and the width and spacing between the conductors are both set to 1.65 $\mathrm{mm}$ to realize a self-complementary structure with an input impedance of $188 \Omega$ at all frequencies [8]. The spiral is fed in anti-phase at two excitation ports located $0.5 \mathrm{~mm}$ apart at the center of the structure. The geometry and dimensions of the 
antenna which was designed to generate predominantly RHCP signals is depicted in Fig. 1(a).

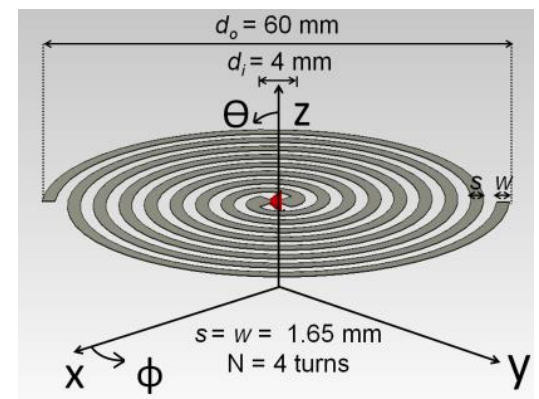

(a)

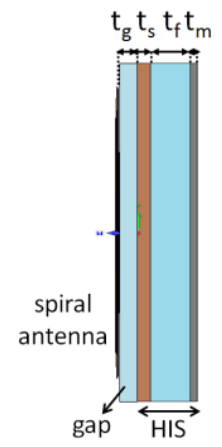

(b)

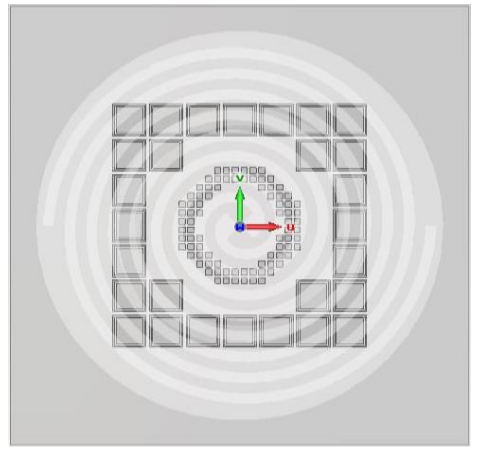

(c)
Fig. 1. (a) Archimedean spiral antenna geometrical parameters; outer diameter $\mathrm{d}_{\mathrm{o}}=60 \mathrm{~mm}$, inner diameter $\mathrm{d}_{\mathrm{i}}=4 \mathrm{~mm}$, spacing $\mathrm{s}=1.65 \mathrm{~mm}$, width $\mathrm{w}=1.65$ $\mathrm{mm}$, number of turns $\mathrm{N}=4$ (b) side view of spiral antenna on HIS with gap $\mathrm{t}_{\mathrm{g}}$ $=1 \mathrm{~mm}$, substrate $\mathrm{t}_{\mathrm{s}}=0.28 \mathrm{~mm}$, foam $\mathrm{t}_{\mathrm{f}}=7.22 \mathrm{~mm}$, metal $\mathrm{t}_{\mathrm{m}}=0.1 \mathrm{~mm}$ (c) top view of array elements of the two HIS reflectors located below the 3 and 6 $\mathrm{GHz}$ active regions of the spiral antenna.

In the computer model the periodic arrays of the HIS were simulated on a $0.28 \mathrm{~mm}$ thick metal backed substrate with $\varepsilon_{\mathrm{r}}=$ 10 and $\tan \delta=0.0035$. The substrate is separated from the ground plane by a $7.22 \mathrm{~mm}$ thick foam spacer $\left(\varepsilon_{\mathrm{r}}=1.05\right)$, and for simplicity a gap $\left(\mathrm{t}_{\mathrm{g}}\right)$ of $1 \mathrm{~mm}$ is inserted between the spiral and HIS as shown in Fig. 1(b). The distance between the radiating aperture and the metal plate is $\approx \lambda / 4$ at $9 \mathrm{GHz}$, therefore for this arrangement a good impedance match and radiation pattern performance is obtained without the need to insert a periodic array under the physical area (radius $=5.3$ $\mathrm{mm}$ ) corresponding to the active region at this frequency. The unit cell dimensions of an infinite array of conductive patches designed to resonate at $3 \mathrm{GHz}$ and $6 \mathrm{GHz}$ are illustrated in Fig. 2(a) and (b) respectively, and the two predicted reflection phase plots are depicted Fig. 2(d). A high permittivity substrate $\left(\varepsilon_{\mathrm{r}}=10\right)$ was employed to reduce the physical size of the patches to enable these to be placed under the active regions of the spiral at radii of $15.9 \mathrm{~mm}(3 \mathrm{GHz})$ and $7.9 \mathrm{~mm}$ $(6 \mathrm{GHz})$ as illustrated in Fig.1 (c). Fig. 3 depicts the computed return loss of three antenna configurations: (i) free space, (ii) backed by the HIS, (iii) backed by a metal plate $\approx \lambda / 4$ distance behind the spiral at $9 \mathrm{GHz}$. The latter two arrangements exhibit a return loss greater than $10 \mathrm{~dB}$ above $4.8 \mathrm{GHz}$, but at lower frequencies the impedance match is observed to be significantly worse than the free space spiral. For example

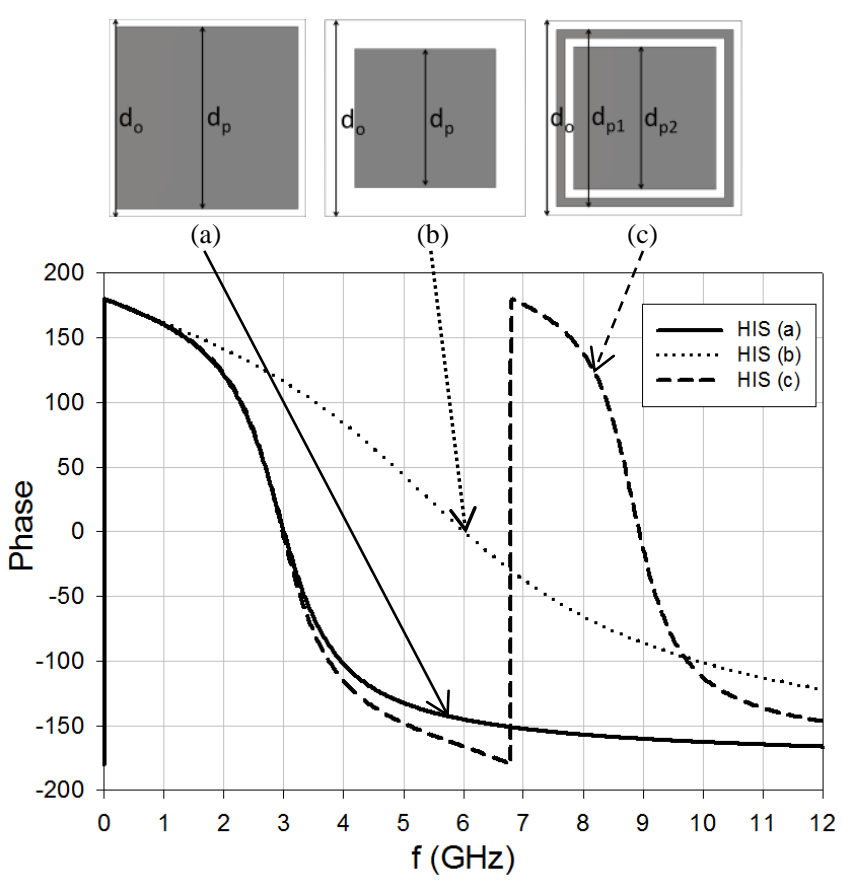

(d)

Fig. 2. Unit cell dimension of the HIS (grey shows metal area) resonant at (a) $3 \mathrm{GHz} ; \mathrm{d}_{\mathrm{o}}=5.2 \mathrm{~mm}, \mathrm{~d}_{\mathrm{p}}=4.8 \mathrm{~mm}$ (b) $6 \mathrm{GHz} ; \mathrm{d}_{\mathrm{o}}=1.02 \mathrm{~mm}, \mathrm{~d}_{\mathrm{p}}=0.72 \mathrm{~mm}$ and (c) $3 \& 9 \mathrm{GHz} ; \mathrm{d}_{\mathrm{o}}=5.6 \mathrm{~mm}, \mathrm{~d}_{\mathrm{p} 1}=5.1 \mathrm{~mm}, \mathrm{~d}_{\mathrm{p} 2}=4.1 \mathrm{~mm}$, (d) predicted reflection phase plots of HIS reflectors.

at $3 \mathrm{GHz}$ the metal plate is very close $(\approx \lambda / 12)$ to the surface of the antenna and the predicted return loss is only about $3 \mathrm{~dB}$. However the results plotted in Fig. 3 (insert) show that a 10 $\mathrm{dB}$ improvement in the return loss is obtained when the antenna is backed by the HIS. Therefore it is evident that the current in the $3 \mathrm{GHz}$ active region of the spiral is not significantly disrupted by the closely spaced outer HIS of the reflector which resonates at the same frequency.

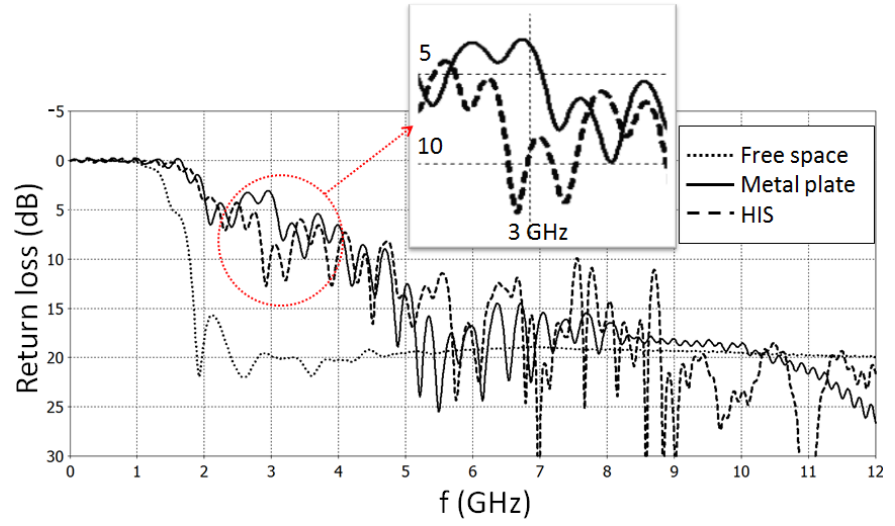

Fig. 3. Predicted return loss, $S_{11}(\mathrm{~dB})$ of antenna in free space, backed by the HIS and a metal plate (unpatterned HIS)

An interesting observation on the radiation pattern performance of the HIS backed antenna is made in Fig. 4(a). This shows that the computed copolar radiation pattern exhibits a $11 \mathrm{~dB}$ null in the boresight direction at $9 \mathrm{GHz}$. At this frequency most radiation occurs from the primary active region of the spiral which is located on a circle with circumference $(\mathrm{C})=\lambda_{9 \mathrm{GHz}}$. However analysis using the $\mathrm{CST}$ 


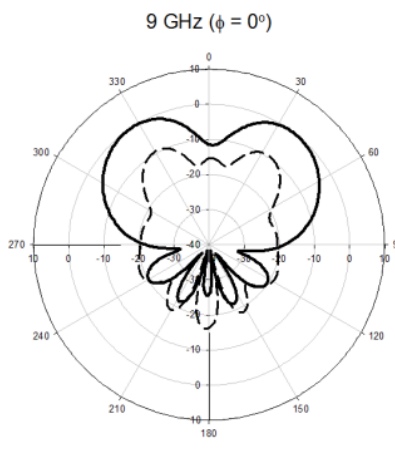

(a)

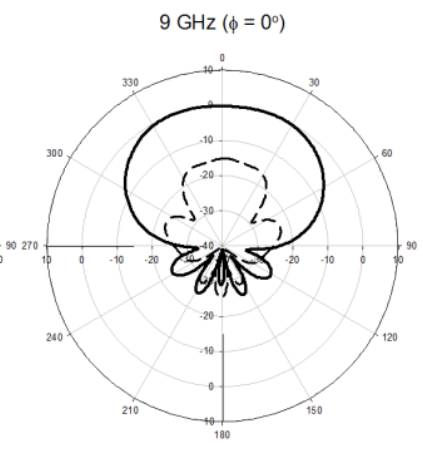

(b)
Fig. 4. Predicted normalized co-polar and cross-polar $\phi=0^{\circ}$ patterns of spiral at $9 \mathrm{GHz}$ with outer (radii of $15.9 \mathrm{~mm}$ ) HIS (a) designed to resonate at $3 \mathrm{GHz}$ - Fig. 2(a), and (b) designed to resonate at $3 \mathrm{GHz} \& 9 \mathrm{GHz}$ - Fig. 2(c).

software shows that higher order mode radiation [9], [10] is induced by the residual (leakage) current which flows in the second active region $\left(\mathrm{C}=3 \lambda_{9 \mathrm{GHz}}\right)$ on a ring of radius $15.9 \mathrm{~mm}$. This is also the location of the first active region of the spiral working at $3 \mathrm{GHz}\left(\mathrm{C}=\lambda_{3 \mathrm{GHz}}\right)$, below which the unit cells of the outer HIS elements are placed. Fig. 2(d) shows that at $9 \mathrm{GHz}$ the reflection phase of this HIS is $160^{\circ}$, therefore the pattern null observed in Fig. 4(a) can be attributed to destructive interference between the primary and higher order mode beams in the boresight direction. To prove that this hypothesis is true we have modified the design of the HIS to remove the pattern null. The unit cell dimensions are depicted in Fig. 2(c), and the predicted reflection phase of the double resonant structure is plotted in Fig. 2(d). At $9 \mathrm{GHz}$ the HIS exhibits a reflection phase of $0^{\circ}$, therefore at this frequency energy radiated from the two active regions is phase matched, and as shown in Fig. 4(b), the desired beam shape is obtained in addition to significantly lower crosspolar levels.

Fig. 5 depicts the normalized predicted copolar (RHCP) and crosspolar (LHCP) radiation patterns for the antenna in free space and placed above the HIS composed of the elements shown in Fig. 2(b) and (c). These are plotted at frequencies of 3,6 and $9 \mathrm{GHz}$ in the $\phi=45^{\circ}$ plane. As a general observation the authors have recently shown that the beam symmetry degrades when a ground plane is used to provide unidirectional operation [11], but for brevity only one pattern cut is presented in this paper because this is sufficient to highlight the improvement in boresight gain and backlobe suppression. The results are summarized in Table I which shows that the predicted realized gain of the HIS backed spiral is more than $3 \mathrm{~dB}$ higher than the free space antenna at $3 \mathrm{GHz}$ and $6 \mathrm{GHz}$, but at $9 \mathrm{GHz}$ the increase is only about $1 \mathrm{~dB}$ because the patterns are broader and the HIS more lossy at this frequency. The predicted reflection loss of the backing structure and total antenna efficiency are $0.1 \mathrm{~dB} / 88 \%(3 \mathrm{GHz})$, $0.05 \mathrm{~dB} / 97 \%(6 \mathrm{GHz})$ and $0.68 \mathrm{~dB} / 89 \%$ (9 GHz). Fig. 5(a) shows that the planar spiral in free space exhibits bidirectional radiation with equal gain and opposite polarizations in the forward and rearward pointing boresight directions. The HIS is shown to suppress the dominant
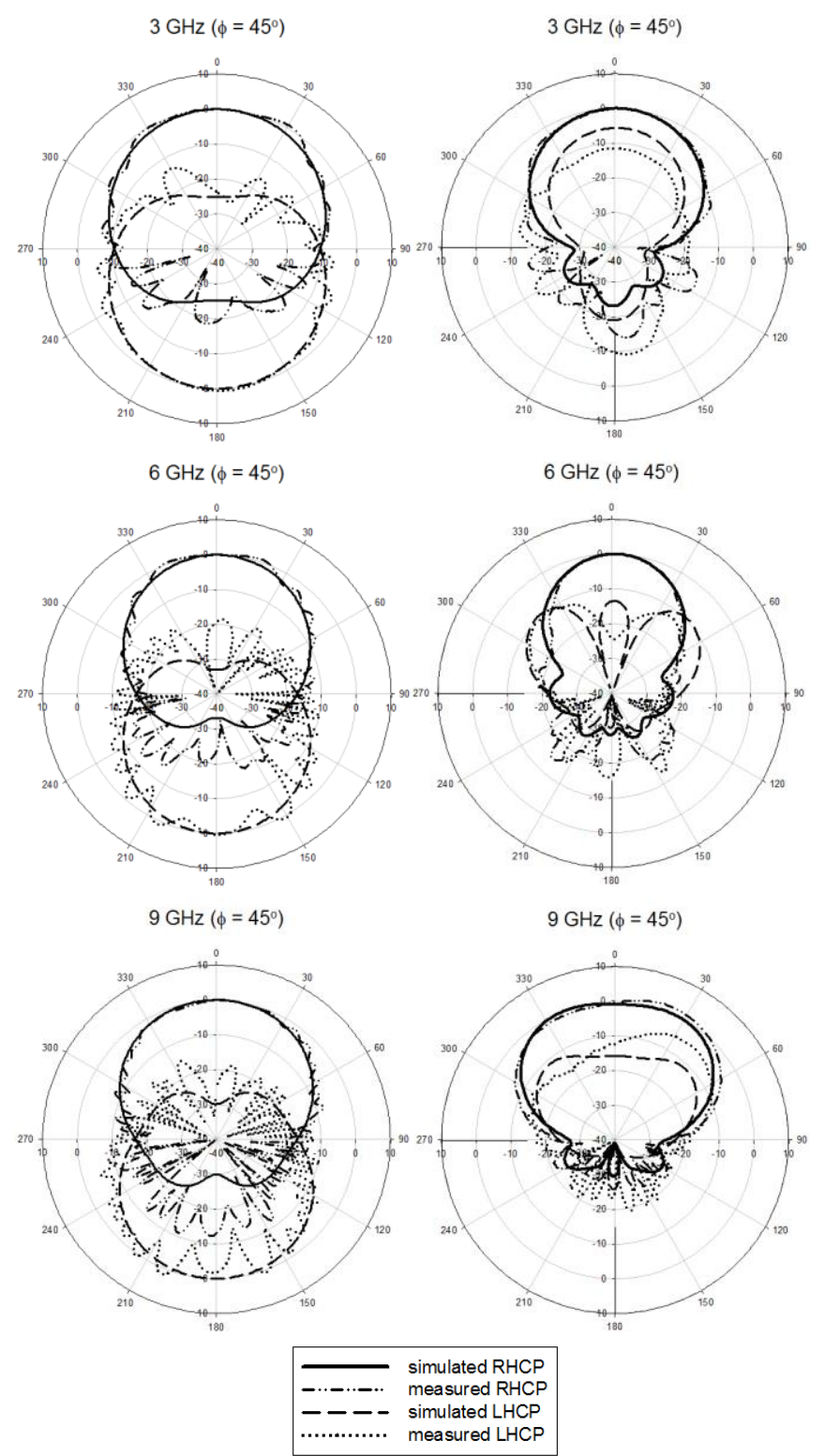

(a)

(b)

Fig. 5. Normalized predicted and measured co-polar and cross-polar radiation patterns of the spiral antenna at $3 \mathrm{GHz}, 6 \mathrm{GHz}$ and $9 \mathrm{GHz}$ (a) free space and (b) with HIS designed to resonate at $3 \mathrm{GHz} \& 9 \mathrm{GHz}$ - Fig. 2(c), and $6 \mathrm{GHz}-$ Fig. 2(b)

crosspolar backlobe radiation from $0 \mathrm{~dB}$ to levels in the range $19 \mathrm{~dB}(3 \mathrm{GHz})$ to $28 \mathrm{~dB}(6 \mathrm{GHz})$. The only drawback of this arrangement is that the polarization purity of the antenna is degraded, particularly at $3 \mathrm{GHz}$. At this frequency the active region is very close to the truncated edge of the spiral so there is minimal attenuation of the residual current which is reflected from the conductor ends. The numerical model was used to study the improvement in the axial ratio of the antenna with resistors inserted at the end of the two arms to suppress the reflected waves [12]. The results obtained for surface mount resistor values of $564 \Omega$ on each arm are shown in brackets in Table 1. The results confirm that the polarization purity is significantly improved albeit at the expense of a small decrease in the antenna gain at $9 \mathrm{GHz}$ and a slightly increase in the front to back ratio. 
TABLE I. CO-POLAR REALIZED GAIN, F/B RATIO AND AXIAL RATIO AT BORESIGHT OF SPIRAL ANTENNA IN FREE SPACE AND WITH HIS AT 3, 6 AND 9

\begin{tabular}{|c|c|c|c|c|c|c|}
\hline \multicolumn{7}{|c|}{$\mathrm{GHz}$} \\
\hline & $\begin{array}{c}3 \mathrm{GHz} \\
\text { Free } \\
\text { space }\end{array}$ & $\begin{array}{c}3 \mathrm{GHz} \\
\text { HIS }\end{array}$ & $\begin{array}{c}6 \mathrm{GHz} \\
\text { Free } \\
\text { space }\end{array}$ & $\begin{array}{c}6 \mathrm{GHz} \\
\text { HIS }\end{array}$ & $\begin{array}{c}\mathrm{GHz} \\
\text { Free } \\
\text { space }\end{array}$ & $\begin{array}{c}9 \mathrm{GHz} \\
\text { HIS }\end{array}$ \\
\hline $\begin{array}{l}\text { Co-polar } \\
\text { realized } \\
\text { gain }\end{array}$ & $\begin{array}{c}4.1 \\
(4.0)\end{array}$ & $\begin{array}{c}7.5 \\
(7.5)\end{array}$ & $\begin{array}{c}5.9 \\
(5.9)\end{array}$ & $\begin{array}{c}9.2 \\
(9.8)\end{array}$ & $\begin{array}{c}6.1 \\
(6.1)\end{array}$ & $\begin{array}{c}7.1 \\
(6.5)\end{array}$ \\
\hline $\mathrm{F} / \mathrm{B}$ ratio & $\begin{array}{c}0 \\
(0)\end{array}$ & $\begin{array}{c}19.0 \\
(18.8)\end{array}$ & $\begin{array}{c}0 \\
(0)\end{array}$ & $\begin{array}{c}28.0 \\
(24.6)\end{array}$ & $\begin{array}{c}0 \\
(0)\end{array}$ & $\begin{array}{c}25.0 \\
(22.9)\end{array}$ \\
\hline $\begin{array}{l}\text { Axial } \\
\text { ratio }\end{array}$ & $\begin{array}{c}1.0 \\
(0.7)\end{array}$ & $\begin{array}{l}10.2 \\
(4.0)\end{array}$ & $\begin{array}{c}0.4 \\
(0.3)\end{array}$ & $\begin{array}{c}3.8 \\
(2.0)\end{array}$ & $\begin{array}{c}0.6 \\
(0.7)\end{array}$ & $\begin{array}{c}3.2 \\
(4.5)\end{array}$ \\
\hline
\end{tabular}

\section{FABRICATION AND EXPERIMENTAL RESULTS}

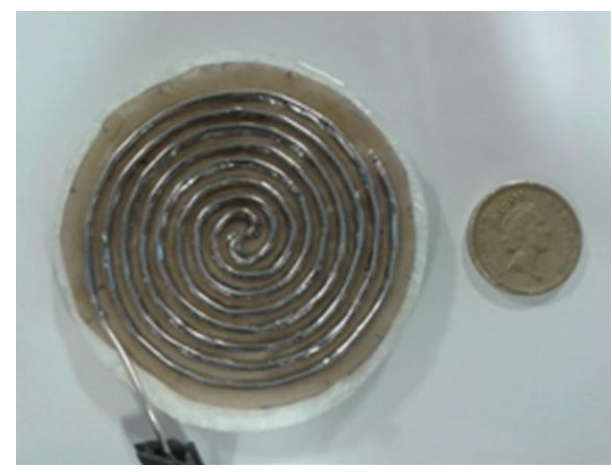

(a)

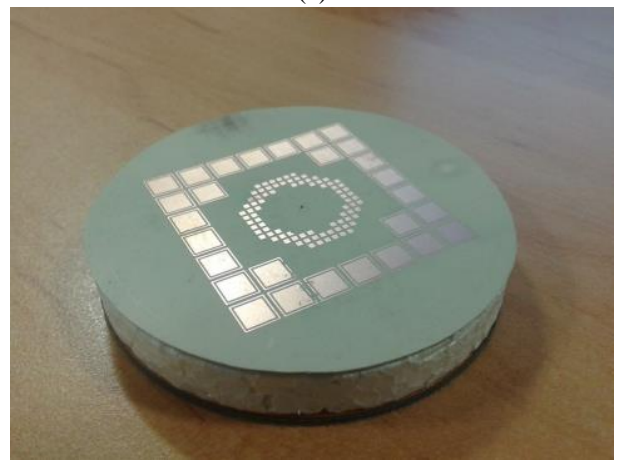

(b)

Fig. 6. Photograph of (a) the Archimedean spiral antenna, (b) HIS

The Archimedean spiral was printed on a $0.13 \mathrm{~mm}$ thick Taconic TLY 5 substrate with $\varepsilon_{\mathrm{r}}=2.2$ and $\tan \delta=0.0009$ and soldered to a $1.1 \mathrm{~mm}$ diameter $50 \Omega$ semi-rigid cable which replicates the spiral's arms. The antenna is excited by an infinite balun and connected to the center feed points which are spaced $0.5 \mathrm{~mm}$ apart as shown in Fig. 6(a). This feed arrangement does not provide an impedance match, however it is simple to construct and suitable for measuring the shape of the radiation patterns [13]. Fig. 6(b) shows a photograph of the HIS which was patterned on a $0.28 \mathrm{~mm}$ thick Taconic CER-10 substrate with $\varepsilon_{\mathrm{r}}=10$ and $\tan \delta=0.0035$. The $1 \mathrm{~mm}$ gap and $7.22 \mathrm{~mm}$ separation distances between the spiral and ground plane were obtained using two Rhoacell $\varepsilon_{\mathrm{r}}=1.05$ low density foam spacers as shown in Fig. 1(b). The radiation patterns of the free space and HIS backed spirals were measured at the three frequencies in an anechoic chamber, and the normalized plots obtained in the $\phi=45^{\circ}$ cut are compared with the simulated results in Fig. 5. Pattern ripple caused by scattering from the support jig located behind the free space antenna is observed at all three frequencies, whereas the beams generated by the HIS backed spiral are much smoother. Both sets of measured data are in close agreement with the simulated results, and highlight the backlobe suppression which is obtained.

\section{CONCLUSION}

In this paper we have used numerical and experimental results to show that carefully designed HIS reflectors can be used to increase the gain and front to back ratio of an Archimedean spiral when these are arranged in a circular pattern and placed under the active regions of the antenna. The design methodology was demonstrated at three frequencies, but this work can be extended to improve the radiation pattern performance in discrete channels over the whole $3-10 \mathrm{GHz}$ operating band of the spiral by deploying multi resonant HIS in either a single layer or stacked arrangement. Moreover our results show that HIS can be used to reduce the thickness of the spiral cavity without compromising the impedance match of the antenna.

\section{REFERENCES}

[1] V. Rumsey, "Frequency independent antennas," IRE International Convention Record, pp. 114-118, 1966.

[2] S. E. Lipsky, "Antenna elements for microwave passive direction finding," in Microwave Passive Direction Finding. Raleigh, NC: SciTech Publishing, pp. 36-63, 2004.

[3] J. Kaiser, "The Archimedean two-wire spiral antenna," IRE Trans. Antennas Propag., vol. 8, no. 3, pp. 312-323, 1960.

[4] R. Cahill, I. Cartmell, G. Van Dooren, K. Clibbon and C. Silence, "Performance of shaped quadrifilar antennas on the METOP spacecraft," IEE. Proc. Microw. Antennas Propag., vol. 145, no. 1, pp. 19-24, 1998.

[5] H. Nakano, K. Nogami, S. Arai, H. Mimaki and J. Yamauchi, "A spiral antenna backed by a conducting plane reflector," IEEE Trans. Antennas and Propag., vol. 34, no. 6, pp. 791-796, 1986.

[6] S. Mohamad, R. Cahill and V. Fusco, "Performance enhancement of a wideband spiral antenna using a stepped ground plane," to be published Microwave Opt. Technol. Lett., vol. 56, no. 3, pp. 753 - 75, Mar 2014.

[7] CST Microwave Studio [Online]. Available: https://www.cst.com/

[8] P. C. Werntz and W. L. Stutzman, "Design, analysis and construction of an Archimedean spiral antenna and feed structure," in IEEE Proc. Energy and Information Technologies in the Southeast, pp. 308-313, 1989.

[9] P. Piksa and M. Mazanek, "Active region and higher-order modes of spiral antennas," in Proc. $6^{\text {th }}$ European Conference on Antennas Propag., pp. 1960-1962, 2012.

[10] M. C. Buck and D. S. Filipovic, "Spiral cavity backing effects on pattern symmetry and modal contamination," IEEE Antennas Wireless Propag. Lett., vol. 5, no. 1, pp. 243-246, 2006.

[11] S. Mohamad, R. Cahill and V. Fusco, "Design of a cavity backed spiral antenna with improved pattern symmetry," in Proc. $7^{\text {th }}$ European Conference on Antennas Propag., pp. 3963-3967, 2013.

[12] P. A. Ramsdale and P. W. Crampton, "Properties of 2-arm conical equiangular spiral antenna over extended bandwidth," IEE Proc. $H$ Microwaves Opt. and Antennas, vol. 128, no. 6, pp. 311-316, 1981.

[13] M. Amin and R. Cahill, "Side-fed bifilar helix antenna," IEEE Microwave and Wireless Components Lett., vol. 15, no. 12, pp. 913915, 2005. 